\title{
Positive o cuidado: site responsivo para a adesão ao tratamento de usuários adultos vivendo com HIV
}

\author{
Vivian Costa Fermo ${ }^{1}$, Francis Solange Vieira Tourinho² ${ }^{2}$ Douglas Dyllon Jerônimo \\ de Macedo $^{3}$
}

\author{
${ }^{1}$ Laboratório de Investigação do Cuidado, Segurança do Paciente, e Inovação \\ Tecnológica em Enfermagem e Saúde (LABTESP) - Universidade Federal de Santa \\ Catarina (UFSC) - Florianópolis - SC - Brasil \\ ${ }^{2}$ Departamento de Enfermagem - UFSC - Florianópolis - SC - Brasil \\ ${ }^{3}$ Departamento de Ciência da Informação - UFSC - Florianópolis - SC - Brasil \\ vivianfermo@hotmail.com, francis.tourinho@ufsc.br, \\ douglas.macedo@ufsc.br
}

\begin{abstract}
Study with the objective of developing information and communication technology with a focus on promoting the treatment of adult users living with HIV. The technological research was carried out through the following steps: (1) technological prospecting; (2) software specification; (3) content construction; (4) software development; and, (5) content validation. The responsive website "Positive care" was developed, with the home screen, which features the site, and 13 other screens that address topics involving HIV treatment. The content of each of the 13 screens reached a Content Validity Index ranging from 0.96 to 1.0 and an Inter-Rater Agreement index of 100\%.
\end{abstract}

Resumo. Estudo com o objetivo de desenvolver tecnologia da informação e comunicação com foco na promoção da adesão ao tratamento de usuários adultos vivendo com HIV. A pesquisa tecnológica foi executada através das seguintes etapas: (1) prospecção tecnológica; (2) especificação do software; (3) construção do conteúdo; (4) desenvolvimento do software; e, (5) validação do conteúdo. Como resultado, desenvolveu-se o site responsivo "Positive o Cuidado", com a tela inicial, que apresenta o site, e outras 13 telas que abordam temas que envolvem o tratamento do HIV. O conteúdo de cada uma das 13 telas alcançou um Índice de Validade de Conteúdo que variou de 0,96 a 1,0 e um indice de Concordância Interavaliadores de 100\%.

\section{Introdução}

A Oganização das Nações Unidas busca, para 2030, o fim da epidemia do HIV/aids com o alcance da meta 95-95-95, ou seja, 95\% das pessoas vivendo com HIV tenham conhecimento sobre o seu status sorológico, 95\% destas em tratamento antirretroviral, sendo que entre estas, 95\% alcancem a supressão da carga viral [UNAIDS 2014]. Como a adesão ao tratamento do HIV é condição essencial para a supressão da carga viral e sucesso do tratamento, a incorporação de tecnologias de informação e comunicação (TIC) na área da saúde têm sido implementada no cuidado às pessoas 
vivendo com HIV no sentindo de promover a retenção à terapia antirerrotrovial (TARV) [Demena et al. 2020].

Neste sentido, surgiu a seguinte pergunta de pesquisa: Qual tipo de TIC, construída a partir de requisitos elencados por profissionais da saúde e pessoas adultas vivendo com HIV, pode contribuir na adesão ao tratamento do HIV? Sustenta-se a tese de que o desenvolvimento de TIC construída a partir de requisitos elencados por profissionais da saúde e pessoas adultas vivendo com HIV, pode contribuir na adesão ao tratamento do HIV. O presente estudo tem por objetivo geral desenvolver TIC com foco na promoção da adesão ao tratamento de usuários adultos vivendo com HIV.

\section{Método}

Trata-se de pesquisa tecnológica executada através das seguintes etapas: (1) prospecção tecnológica; (2) especificação do software; (3) construção do conteúdo; (4) desenvolvimento do software; e, (5) validação do conteúdo.

\subsection{Procedimentos metodológicos - Etapa 1: prospecção tecnológica}

A prospecção tecnológica foi realizada através de revisão integrativa de literatura e de pequisa documental. A revisão integrativa de literatura objetivou conhecer as TIC utilizadas por pessoas que vivem com HIV para a adesão ao tratamento. A busca foi realizada, através do acesso ao portal CAPES, pelo sistema CAFE em abril de 2018, nas bases de dados Medical Literature Analysis and Retrieval System Online/National Library of Medicine National Institutes of Health (Medline/Pubmed), Scopus, Scientific Electronic Library Online (Scielo), Literatura Latino-americana e do Caribe em Ciências da Saúde (Lilacs) e IEEE Xplore, através de tesauros controlados do DECS/MESH que se referiam a tecnologias de informação e comunicação, tratamento antiretroviral e ao HIV. Foram definidos os seguintes critérios de inclusão: artigos que façam referência e tragam o resultado do uso de TICs para promover a adesão ao tratamento por pessoa que vive com HIV; disponíveis em espanhol, inglês ou português; publicados entre 01 de janeiro de 2008 e 31 de dezembro de 2017. Foram excluídos: teses; dissertações; resumos de trabalhos publicados em anais de eventos; editorial; cartas ao editor; artigos não disponíveis na íntegra online; artigos disponíveis online que são pagos; revisões de literatura; e estudos que não correspondam ao escopo dessa revisão. A amostra final foi constituída por 57 estudos (56 da Pubmed e 1 da Scopus).

A prospecção tecnológica realizada através de pesquisa documental com abordagem qualitativa, teve por objetivo identificar aplicativos móveis, disponíveis para a cultura brasileira, que promovam conhecimentos ou informações acerca do HIV/Aids. A coleta dos dados ocorreu em janeiro de 2019. A busca por aplicativos foi realizada através de acesso as lojas virtuais Apple Store ${ }^{\circledR}$, em 12 de janeiro de 2019, e Google Play ${ }^{\circledR}$, em 17 de janeiro de 2019. Os critérios de inclusão foram: aplicativos que abordem o tema HIV/Aids com foco no seu tratamento e controle. Critérios de exclusão: aplicativos sobre eventos científicos voltados a profissionais, que não relatavam em sua descrição que trariam a disponibilização das publicações científicas do evento; diretrizes e protocolos clínicos não brasileiros. Na estratégia de busca utilizou-se as palavras-chave: HIV e aids. Foram captados 13 aplicativos na Google Play ${ }^{\circledR}$ e 19 aplicativos na Apple Store ${ }^{\circledR}[$ Fermo et al. no prelo]. 


\subsection{Procedimentos metodológicos - Etapa 2: especificação do software}

Estudo descritivo-exploratório com abordagem qualitativa. Objetivou elencar os requisitos para desenvolvimento de TIC com foco em promover a adesão ao tratamento do usuário adulto vivendo com HIV. O estudo foi realizado na Secretaria Municipal de Saúde de Florianópolis e em um grupo de apoio a prevenção da aids de Santa Catarina, localizado no mesmo município.

Foram convidados a participar do estudo profissionais da saúde e pessoas vivendo com HIV. Foram considerados como critérios de inclusão para os enfermeiros e médicos que atuam na Atenção Primária à Saúde (APS): ter realizado o treinamento outreach education do PACK Brasil Adulto no período 2016/2017 e que realizam atendimento integral à pessoa vivendo com HIV na APS. Para os profissionais que atuam no Serviço de Atenção Especializada (SAE), o único critério foi realizar atendimento assistencial direto à pessoa vivendo com HIV. Foi elencado como critério de exclusão: estar afastado do trabalho no período da coleta de dados. A amostra foi do tipo intencional não probabilística. Referente às pessoas vivendo com HIV, foi elencado como critério de inclusão: estar em uso de TARV há seis meses ou mais, ter 18 anos de idade ou mais e realizar acompanhamento para o HIV na APS do município de Florianópolis. Foram elencados como critério de exclusão: não saber ler e escrever. A amostra se deu por conveniência.

A coleta de dados se deu através de sessões de brainstorm, sendo que, na primeira, realizada no dia 10 de julho de 2019 participaram os profissionais da saúde (dois enfermeiros e três médicos da Estratégia Saúde da Família (ESF) e dois farmacêuticos que atuam no SAE, e na segunda, realizada em 09 de outubro de 2019, participaram cinco pessoas vivendo com HIV. Nas sessões, foram elencados os requisitos que seriam importantes estar presentes em uma TIC para uso da pessoa vivendo com HIV com o foco na adesão ao tratamento. Após, entre 10 e 25 de outubro de 2019 foram realizadas entrevistas individuais com três pessoas vivendo HIV. Após estas entrevistas, identificou-se que todos os requisitos trazidos já haviam sido abordados nas sessões de brainstorm anteriores, e foi finalizada a coleta de dados, devido saturação teórica.

\subsection{Procedimentos metodológicos - Etapa 3: construção do conteúdo}

Pesquisa metodológica com o objetivo de apresentar o processo de construção de conteúdo de uma tecnologia de informação e comunicação voltada a promover a adesão ao tratamento dos usuários adultos vivendo com HIV. O processo de construção do conteúdo foi delineado a partir de adaptações no modelo de Pasquali (2010), com o desenvolvimento da etapa de procedimentos teóricos, no qual se identificaram os itens e foram construídos os conteúdos para posterior desenvolvimento da TIC pretendida. A fase Teoria foi realizada entre setembro de 2017 e outubro de 2019 e a fase de Construção entre novembro de 2019 a junho de 2020.

\subsection{Procedimentos metodológicos - Etapa 4: desenvolvimento do software}

Estudo tecnológico, em que se descreve o processo de desenvolvimento de site responsivo com foco na adesão ao tratamento de usuários adultos vivendo com HIV. Há quatro atividades fundamentais na engenharia de software: especificação do software; desenvolvimento do software; validação do software; e evolução do software 
[Sommerville 2011]. O presente estudo reporta a atividade desenvolvimento do software, que foi composta pelas fases: processo de design e programação do software.

O processo de design foi realizado através da metodologia Double Diamond Process [Design Council 2020] associada aos cinco planos definidos pelo framework chamado The Elements of User Experience, desenvolvido por Garret (2011). O desenvolvimento do software foi realizado entre agosto e outubro de 2020.

\subsection{Procedimentos metodológicos - Etapa 5: validação do conteúdo}

Estudo metodológico no qual ocorreu a validação de conteúdo do site responsivo Positive o Cuidado, que tem como foco a promoção do tratamento de usuários adultos vivendo com HIV. O processo de validação de conteúdo foi delineado a partir de adaptações no modelo de Pasquali (2010), com o desenvolvimento das etapas de procedimentos empíricos (entre 26 de outubro e 15 de novembro de 2020) e analíticos. O referencial metodológico adotado [Pasquali 2010], orienta um número de seis a vinte juízes no processo de validação de instrumentos. A seleção de juízes deu-se por conveniência. Participaram seis profissionais (três enfermeiros e três médicos) que compõem equipes da Estratégia de Saúde de Família do município de Florianópolis. O instrumento de pesquisa foi criado a partir da ferramenta eletrônica Google Forms ${ }^{\circledR}$, contendo os critérios de Pasquali (2010): comportamental, objetividade, simplicidade, clareza, relevância, precisão, variedade, modalidade, tipicidade, credibilidade, amplitude e equilíbrio. Os primeiros dez critérios serão utilizados para avaliar cada item do construto e os dois últimos para avaliar o conjunto de itens.

Para a estratégia de validação de conteúdo foi utilizado o Índice de Validade de Conteúdo - IVC e a Concordância Interavaliadores - CI, sendo que ambos devem chegar a valores acima de $80 \%(0,8)$ para serem confiáveis [Rubio et al. 2003].

\subsection{Aspectos éticos}

A pesquisa seguiu os preceitos da resolução do CNS n. 466/2012 e foi aprovada pelo Comitê de Ética em Pesquisa com Seres Humanos sob número CAAE 03609118.6.0000.0121.

\subsection{Referencial teórico-filosófico}

Optou-se por adotar Pierry Levy (2004; 2010a; 2010b) como referencial teóricofilosófico, visto que traz a tecnologia como um produto do saber que influencia as profissões do nível terciário a melhor servirem à sociedade através da sua mercadoria e discute temas importantes como: a evolução das formas de comunicação na sociedade; as técnicas e as tecnologias; a inteligência coletiva; e o ciberespaço.

\section{Resultados}

\subsection{Etapa 1: prospecção tecnológica}

$\mathrm{Na}$ revisão integrativa de literatura foi identificado o uso das seguintes tecnologias: SMS, chamadas telefônicas, aplicativos de smartphone, dispositivos de monitoramento de aderência eletrônica em tempo real (MAETR), chamada de resposta de voz interativa automatizada, enfermeira virtual, suporte interativo via computador/internet, vídeo motivacional, programa de áudio, programa de computador via web/websites, videofone 
e telemedicina. Em alguns estudos as tecnologias foram utilizadas isoladamente, enquanto em outros foram associadas. Os impactos na adesão ao tratamento foram diversos, sendo que algumas TIC promoveram a adesão ao tratamento, enquanto outras não.

Quanto aos aplicativos disponíveis na Apple Store ${ }^{\circledR}$ e Google Play®, estão voltados aos usuários do sistema de saúde, profissionais da saúde e população em geral, e suas funções vão ao encontro das estratégias de prevenção combinada em suas três categorias de intervenções (biomédicas, comportamentais e estruturais). Em relação as tecnologias voltadas especificamente as pessoas que vivem com HIV, tiveram como foco em: interação social entre os pares; gestão do tratamento medicamentoso e da rotina de acompanhamento à saúde; e, divulgação de conteúdos e conscientização da importância do tratamento antirretroviral. Dos dois aplicativos que receberam avaliação pelos usuários, um recebeu críticas quanto ao valor para assinantes, e o outro quanto a não atualização do sistema operacional após as críticas dos seus usuários, o que pode repercutir negativamente na usabilidade do produto [Fermo et al. no prelo].

\subsection{Etapa 2: especificação do software}

Foram identificados 49 requisitos, organizados em dez categorias empíricas: 1) motivacionais para a adesão ao tratamento; 2) uso de antirretrovirais; 3) exames laboratoriais e consultas; 4) interação com outros usuários e com profissionais da saúde; 5) vida saudável; 6) prevenção combinada; 7) comunicação às parcerias e planejamento familiar e reprodutivo; 8) funções personalizáveis; 9) assistência interdisciplinar; e, 10) curiosidades e novidades.

\subsection{Etapa 3: construção do conteúdo}

Com os requisitos identificados, foram definidos aqueles que seriam implementados em um produto mínimo viável (MVP). Optou-se pelo site responsivo para atender as necessidades dos usuários. A escolha se deu em virtude de o site responsivo possibilitar a sua atualização pelo próprio pesquisador, quando necessário realizar a evolução do software frente as novas necessidades dos usuários, o que potencializa a usabilidade do produto. Diante da decisão quanto ao tipo de tecnologia a ser construída e os requisitos a serem implementados, deu-se início a fase de construção do conteúdo. Com base nos requisitos foram construídos os itens do construto. Para a construção de conteúdo dos itens, utilizou-se a literatura nacional e internacional, protocolos nacionais e municipais, com o objetivo de abordar os temas necessários para atender os requisitos da tecnologia. Os conteúdos foram produzidos nas seguintes ferramentas: Microsoft word $\AA$, Microsoft excel ${ }^{\circledR}$, podcast (gravador de voz de smartphone) com publicação em plataforma

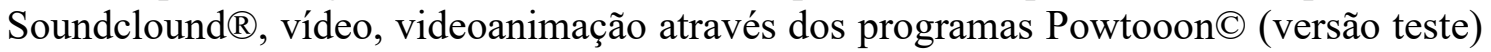
e Sparkol VideoScribe C (versão paga) com download na plataforma Youtube $C$. Os

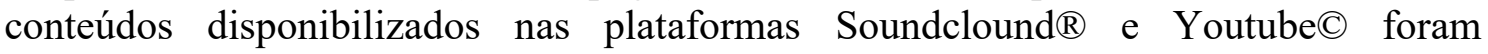
posteriormente agregados ao site responsivo. Após os conteúdos construídos, foram criados protótipos de baixa fidelidade para cada item proposto, contendo os seus conteúdos.

\subsection{Etapa 4: desenvolvimento do software}

A partir dos protótipos das telas construídos pelo pesquisador, foi realizada a disponibilização do conteúdo no site responsivo, através da programação da TIC por 
profissional designer. O site responsivo "Positive o Cuidado" está disponível através do hiperlink "www.positiveocuidado.com", destinado às pessoas vivendo com HIV no município de Florianópolis, composto por uma tela inicial de apresentação e outras 13 telas que respondem aos requisitos identificados em etapa de especificação do software. Para abordagem aos conteúdos, foram utilizadas diversas ferramentas, como recursos de vídeos, vídeo-animações, textos, imagens/ilustrações, podcasts e hiperlinks para outras plataformas digitais. Conta com a possibilidade do usuário entrar em contato com a

responsável pela Plataforma através do WhatsApp ${ }^{\circledR}$ e do e-mail duvidas@positiveocuidado.com.

\subsection{Etapa 5: validação do conteúdo}

Em relação a avaliação dos conteúdos, cada uma das 13 telas alcançou um Índice de Validade de Conteúdo que variou de 0,96 a 1,0 e um Índice de Concordância Interavaliadores de $100 \%$. Assim, o conteúdo mostrou-se válido, com coerência entre os juízes na avaliação, representando uma fonte segura e atualizada de informações para as pessoas vivendo com HIV.

\section{Referências}

Demena, B. A., Artavia-Mora, L., Ouedraogo, D., Thiombiano, B. A. and Wagner, N. (2020). Adherence and Retention to Antiretroviral Treatment in Low-and MiddleIncome Countries. AIDS Patient Care and STDs, v. 34, n. 2. Disponível em: https://www.liebertpub.com/doi/full/10.1089/apc.2019.0181. Acesso em: 24 set.

Design Council (2020). What is the framework for innovation? Design Council's evolved Double Diamond. Disponível em: https://www.designcouncil.org.uk/newsopinion/what-framework-innovation-design-councils-evolved-double-diamond.

Fermo, V. C., Tourinho, F. S. V., Schuelter, P. I., Macedo, D. D. J., Alves, T. F. and Fagundes, P. B. (no prelo). Mobile applications on HIV/aids: a technological prospection. Revista Online de Pesquisa Cuidado é Fundamental.

Garrett, J. J. (2011). Elements of user experience, the: user-centered design for the web and beyond. Pearson Education. 2a edição.

Lévy, P. (2010a) As tecnologias da inteligência: o futuro do pensamento na era da informática. $2^{\text {a }}$ ed. Rio de Janeiro: Editora 34.

Lévy, P. (2010b). Cibercultura. $3^{\text {a }}$ ed. São Paulo: Editora 34.

Lévy, P. (2004). Inteligencia colectiva: por una antropología del ciberespacio.

Pasquali, L. (2010). Instrumentação psicológica: fundamentos e práticas. Porto Alegre: Artmed.

Rubio, D. M., Berg-Weger, M., Tebb, S. S., Lee, S. and Rauch, S. (2003). Objectifying content validity: Conducting a content validity study in social work research. Social Work Research, v. 27, n. 2, p. 94-105.

UNAIDS (2014). Acabar com a pandemia da AIDS: cidades acelerando a resposta para alcançar as metas 90-90-90 até 2020. 2014. Disponível em: https://unaids.org.br/wp/content/uploads/2015/12/Declara\%C3\%A7\%C3\%A3o-deParis-PORT-1.pdf. Acesso em: 28 fev. 2020. 